\title{
Fetal Alcohol Syndrome with Hydrocephalus
}

\section{Bilge TANYERİ-BAYRAKTAR', Süleyman BAYRAKTAR², Merve HEPOKUR ${ }^{1}$, Murat KARDAŞ}

${ }^{1}$ Department of Neonatology, Bezmialem Vakif University Faculty of Medicine, Istanbul, Turkey

${ }^{2}$ Clinic of Pediatrics, Haseki Training and Research Hospital, Istanbul,Turkey

\section{ABSTRACT}

Exposure to alcohol in the fetal period leads to various structural abnormalities and this is called as fetal alcohol syndrome. Cranial and facial anomalies are the common features of fetal alcohol syndrome. Microcephaly is frequently associated with fetal alcohol syndrome, but hydrocephalus may be rarely seen.

The female baby at a gestational age of 33 weeks and with a weight of $2000 \mathrm{~g}$ was born prematurely at our hospital from a mother of a foreign nationality. The baby had dysmorphic features and macrocephalus. The mother drank $1 \mathrm{~L}$ alcohol per day during pregnancy. The baby was admitted to the neonatal intensive care unit for prematurity, hydrocephalus, and fetal alcohol syndrome.

In our country, alcohol use in women, particularly pregnant women, is a very rare condition because of community rules and beliefs. In this report, we highlighted fetal alcohol syndrome and its coexistence with hydrocephalus.

Keywords: Fetal alcohol syndrome, hydrocephalus, prematurity

\section{Introduction}

In recent years, the prevalence of the use of alcohol has been increasing among women (1). The use of alcohol among pregnant women and women in the reproductive age group is an important public concern in the United States of America (2). The rate of planned pregnancy is low among women living in the United States of America, and most women drink alcohol without being aware of their pregnancy. The prevalence of alcohol consumption among parturients has been reported to vary between $12 \%$ and $15 \%$ in recent years. Prenatal alcohol exposure is a frequent teratogenic cause of developmental disorders, congenital defects, and mental diseases (3).

\section{Case Presentation}

A female baby weighing $2000 \mathrm{~g}$ was born through normal spontaneous vaginal delivery at the $33^{\text {rd }}$ gestational week in the first pregnancy of her 20-year-old mother. The baby was macrocephalic, and her head circumference was $45 \mathrm{~cm}(>95$ percentile). Her face was dysmorphic, and she had micrognathia, a smooth philtrum, and a thin upper lip (Figure 1). The patient was hypoactive, and her newborn reflexes were poor. She could not close her eyelids, and her cornea was blurred. It was learned that her mother, who was of foreign nationality, drank approximately $1 \mathrm{~L}$ of alcohol per day before and during pregnancy. The baby was admitted to the neonatal intensive care unit for the pre-diagnoses of prematurity and fetal alcohol syndrome (FAS).

In her laboratory evaluation, complete blood count and biochemistry values were normal. Moreover, the results of examinations performed for intrauterine viral infections (TORCH infections) were found to be normal. No numerical and structural chromosome anomaly was observed in the chromosome analysis (46XX). On cranial computed tomography, ventricles were observed to be severely dilated and the corpus callosum could not be viewed. The brain parenchyma could be monitored in partially frontal area (Figure 2). The result of the echocardiographic examination was normal. The neurosurgery department was consulted, and ventricular tapping was performed. The mother rejected the insertion of a ventriculoperitoneal shunt in the baby. In the evaluation performed by the department of ophthalmology, bilateral exposure keratopathy, bilateral central corneal opacity, and corneal edema were detected. On the $17^{\text {th }}$ day of the follow-up period, the baby had cardiac arrest and became exitus.

Necessary permission was received from the mother for using the pictures of the baby. 


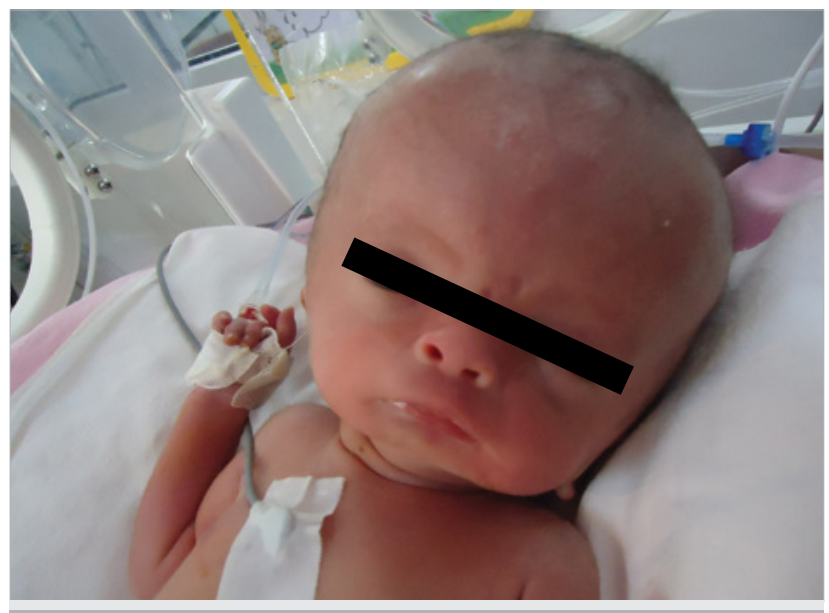

Figure 1. Facial appearance of the hydrocephalic baby with fetal alcohol syndrome

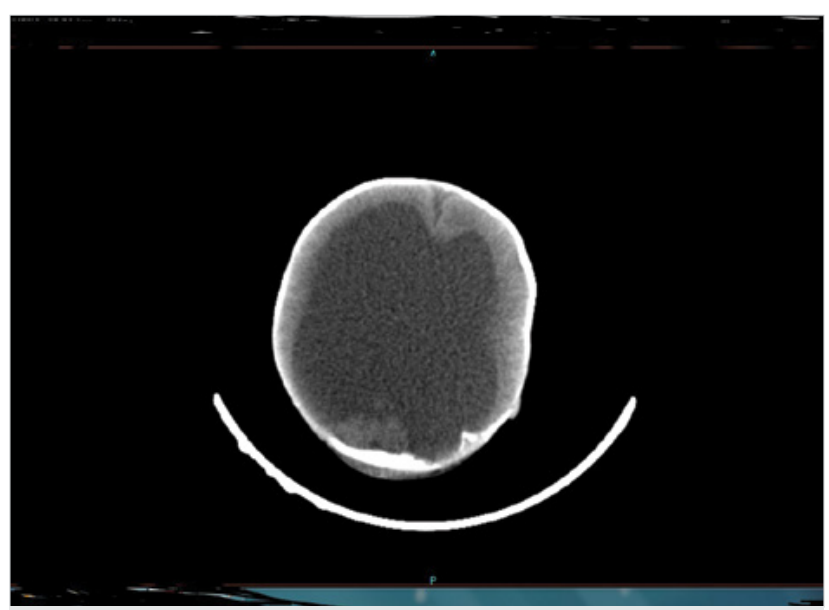

Figure 2. Cranial computed tomography image of the hydrocephalic baby with fetal alcohol syndrome

\section{Discussion}

Alcohol addiction in mothers causes abnormal fetal development; this condition is defined as FAS. FAS is characterized by central nervous system dysfunction, pre- and post-natal growth retardation, cranial and facial anomalies, and organ anomalies. When the central nervous system is involved, the most serious disorders are mental retardation, motor dysfunction, and ataxia. Exposure to alcohol during the intrauterine period is the most commonly known cause of mental retardation in the United States of America.

The prevalence of fetal alcohol spectrum disorders is 9.1 per 1000 live births (4). Recently, it has been determined that prenatal alcohol exposure is an important factor for mortality during the fetal period, infancy, and childhood (3).

FAS was first defined by Jones and Smith in 1973 (5). Prenatal alcohol exposure is a cause of congenital brain anomalies (6). Hydrocephalus is an uncommon anomaly among patients with FAS; microcephaly is more frequently seen (7). The causes and neuropathological aspects of hydrocephalus are not well known. The most common and well-defined type of hydrocephalus is X-linked, and it is related to the mutation in L1 gene coding region. Brain dysfunction and malformations associated with FAS occur in patients having a mutation in this region. Ethanol is teratogen, and it has been revealed that it affects the brain by blocking the molecular interaction formed by L1 (8). The exposure of fetal cells to ethanol can lead to dysmorphic features (smooth philtrum, thin upper lip, small palpebral fissures, upturned nostrils, and microcephaly), other congenital anomalies, neurodevelopmental anomalies, and neuroanatomic defects (4).

The most harmful form of alcohol consumption for the fetus is heavy episodic drinking. In babies of pregnant women who continue to drink alcohol during pregnancy and consume more alcohol than usual, the occurrence of FAS with severe dysmorphic features is highly probable. Moreover, the age and social status of mothers can affect the development of FAS (9). In children with FAS, neuronal-glial heterotopias, cerebellar dysplasia, corpus callosum agenesis, and microcephaly from neuropathological abnormalities can be encountered (10). In our case, the mother had a history of heavy alcohol consumption during pregnancy, and severe FAS findings were detected in the baby.

\section{Conclusion}

In Turkey, the use of alcohol among pregnant women is uncommon. Therefore, we could not find a study conducted on this issue in Turkey in literature. Moreover, in literature, there are a few studies on cases of FAS coexisting with hydrocephalus. With this case, we aimed to highlight FAS, which is rarely found among the causes of hydrocephalus in Turkey.

Informed Consent: Written informed consent was obtained from the patient's parents.

Peer-review: Externally peer-reviewed.

Author Contributions: Concept - B.T.B., S.B.; Design - B.T.B.; Supervision S.B.; Funding -M.H.; Materials - M.K.; Data Collection and/or Processing - M.H., M.K.; Analysis and/or Interpretation - S.B.; Literature Review - M.H., M.K.; Writer - B.T.B.; Critical Review - S.B.

Conflict of Interest: The authors declared no conflict of interest.

Financial Disclosure: The authors declared that this study has received no financial support.

\section{References}

1. Smith LA, Foxcroft DR. The effect of alcohol advertising, marketing and portrayal on drinking behaviour in young people: Systematic review of prospective cohort studies. BMC Public Health 2009; 9: 51. [CrossRef]

2. Centers for Disease Control and Prevention. Alcohol use among pregnant and nonpregnant women of childbearing age - United States, 1991-2005. MMWR Morb Mortal Wkly Rep 2009; 58: 529-32.

3. Li Q, Fisher WW, Peng CZ, Williams AD, Burd L. Fetal Alcohol Spectrum Disorders: A Population Based Study of Premature Mortality Rates in the Mothers. Matern Child Health J 2012; 16: 1332-7. [CrossRef] 
4. Sampson PD, Streissguth AP, Bookstein FL, Little RE, Clarren SK, Dehaene P, et al. Incidence of fetal alcohol syndrome and prevalance of alcohol-related neurodevelopmental disorder. Teratology 1997; 56: 317-26. [CrossRef]

5. Tenenbaum A, Herzt P, Dor T, Castiel Y, Sapir A, Wexler ID. Fetal Alcohol Spectrum Disorder in Israel: Increased Prevalence in an At-Risk Population. Isr Med Assoc J 2011; 13: 725-9.

6. Jones KL. The Effects of Alcohol on Fetal Development. Birth Defects Res C Embryo Today 2011; 93: 3-11. [CrossRef]

7. Goez HR, Scott O, Hasal S. Fetal exposure to alcohol, developmental brain anomaly, and vitamin a deficiency: a case report. J Child Neurol 2011; 26: 231-4. [CrossRef]
8. Ramanathan R, Wilkemeyer MF, Mittal B, Perides G, Charness ME. Alcohol inhibits cell-cell adhesion mediated by human L1. J cell Biol 1996; 133: 381-90. [CrossRef]

9. May PA, Tabachnick BG, Gossage JP, Kalberg WO, Marais AS, Robinson LK, et al. Maternal risk factors predicting child physical characteristics and dysmorphology in fetal alcohol syndrome and partial fetal alcohol syndrome. Drug Alcohol Depend 2011; 119: 18-27. [CrossRef]

10. Sakata-Haga H, Sawada K, Ohnishi T, Fukui Y. Hydrocephalus following prenatal exposure to ethanol. Acta Neuropathol 2004; 108: 393-8. [CrossRef] 